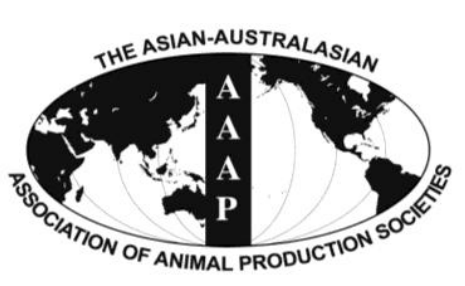

Open Access

Asian Australas. J. Anim. Sci.

Vol. 27, No. 1 : 101-114 January 2014

http://dx.doi.org/10.5713/ajas.2013.13325

www.ajas.info

pISSN 1011-2367 elSSN 1976-5517

\title{
Goat Meat Does Not Cause Increased Blood Pressure
}

\author{
Katsunori Sunagawa*, Tetsuya Kishi, Ayako Nagai, Yuka Matsumura, \\ Itsuki Nagamine, and Shuntoku Uechi \\ Faculty of Agriculture, University of the Ryukyus, 1 Senbaru, Nishihara-cho, Okinawa 903-0213, Japan
}

\begin{abstract}
While there are persistent rumors that the consumption of goat meat dishes increases blood pressure, there is no scientific evidence to support this. Two experiments were conducted to clarify whether or not blood pressure increases in conjunction with the consumption of goat meat dishes. In experiment 1, 24 Dahl/Iwai rats (15 weeks old, body weight $309.3 \pm 11.1 \mathrm{~g}$ ) were evenly separated into 4 groups. The control group (CP) was fed a diet containing $20 \%$ chicken and $0.3 \%$ salt on a dry matter basis. The goat meat group (GM) was fed a diet containing $20 \%$ goat meat and $0.3 \%$ salt. The goat meat/salt group (GS) was fed a diet containing $20 \%$ goat meant and 3\% to 4\% salt. The Okinawan mugwort (Artemisia Princeps Pampan)/salt group (GY) was fed a diet containing 20\% goat meat, $3 \%$ to $4 \%$ salt and 5\% of freeze-dried mugwort powder. The experiment 1 ran for a period of 14 weeks during which time the blood pressure of the animals was recorded. The GS, and GY groups consumed significantly more water $(p<0.01)$ than the CP and GM groups despite the fact that their diet consumption levels were similar. The body weight of animals in the CP, GM, and GS groups was similar while the animals in the GY group were significantly smaller $(\mathrm{p}<0.01)$. The blood pressure in the GM group was virtually the same as the CP group throughout the course of the experiment. In contrast, while the blood pressure of the animals in the GS and GY group from 15 to 19 weeks old was the same as the CP group, their blood pressures were significantly higher $(\mathrm{p}<0.01)$ after 20 weeks of age. The GY group tended to have lower blood pressure than the GS group. In experiment 2, in order to clarify whether or not the increase in blood pressure in the GS group and the GY group in experiment 1 was caused by an excessive intake of salt, the effects on blood pressure of a reduction of salt in diet were investigated. When amount of salt in the diet of the GS and GY group was reduced from $4 \%$ to $0.3 \%$, the animal's blood pressure returned to normotensive. These results indicate that, as in the case of chicken consumption, prolonged consumption of goat meat does not cause increased blood pressure, rather the large amount of salt used in the preparation of goat meat dishes is responsible for the increase in blood pressure. (Key Words: Goat Meat Dish, Blood Pressure, Salt Intake, Mugwort)
\end{abstract}

\section{INTRODUCTION}

During the period of food shortages following WWII (1945 to 1965), there was a severe shortage of animal protein for human consumption in Okinawa and the Asia region. It was reported that dishes of goat meat were used as a medicinal food and this was credited with saving many lives in Okinawa (Hirakawa, 2008). During the period of stable growth in the Japanese economy (1966 to 1989), pork, eggs, milk, and chicken gradually became more readily available. Despite this, people in Okinawa showed a

\footnotetext{
* Corresponding Author: K. Sunagawa. Tel: +81-98-895-8798, Fax: +81-98-895-8734, E-mail: b986094@ agr.u-ryukyu.ac.jp Submitted Jun. 7, 2013; Accepted Aug. 23, 2013; Revised Aug. 30, 2013
}

strong preference for goat meat dishes. Goat meat dishes were a special treat served at celebrations, welcome parties, social gatherings, and housewarmings. However, from 1990, Japan entering an age of plentiful food supply and with the persistent rumor that goat meat dishes increase blood pressure, the number of people in Okinawa who dislike the traditional dishes has increased. However, there is absolutely no scientific evidence to support the rumors surrounding goat meat dishes.

Goat meat dishes served in Okinawa include, soup, sashimi (raw slices of meat), and Chiiricha (a dish of stir fried vegetables that uses goats blood as an ingredient). Of these dishes, the most common is soup. Goat meat soup is made from an entire goat. The bones with the meat still on them, and internal organs etc are all placed in a large pot 
and stewed for 3 to $4 \mathrm{~h}$ to create a fragrant and tasty soup. The soup is seasoned with salt (approx. 2.5\%) on the main island of Okinawa while in some of the outlying islands miso paste (ferment soy bean paste) is added for flavor. It has been reported that Okinawan mugwort (Artemisia Princeps Pampan) contains bioactive functional components including sitosterol, cineol and rutin. Furthermore, it was reported to suppress arteriosclerosis and the creation of lipid peroxide, and has antipyretic, antianalgesic, and anti-inflamatory effects (Chen et al., 1994; Sugimoto et al., 1998). Mugwort has traditionally been used in goat meat soup as a medicinal ingredient and flavor enhancer.

Goats are herbivores well known for their ability to survive on a variety of grasses and leaves. As with other meats, goat meat is mainly constituted from protein and fat. Protein in goat meat is well balanced with essential and non-essential amino acids. It also contains high levels of taurine, carnitine, and inosine that are important for human health (Nagamine et al., 2013). The fat in goats contains approximately $50 \%$ saturated fatty acids and $50 \%$ unsaturated fatty acids with high levels of oleic acid (C18:1) (Nagamine et al., 2013). It is therefore thought that the high blood pressure observed in people who consume goat meat dishes is attributable to the condiments used to flavor the dishes rather than the meat itself.

The energy produced by the heart stroke applies lateral pressure to the blood vessel walls and facilitates movement of the blood. The energy not used in facilitating movement of the blood is dissipated as frictional heat. Blood pressure is dictated by the minute cardiac stroke volume and peripheral vascular vessel resistance. Hypertension is classified into two groups, essential hypertension, and secondary hypertensions that are brought about in response to a causative disease. While the cause of essential hypertension is unclear, more than $90 \%$ of high blood pressure sufferers show evidence of inherited genetic factors from parental hypertensive diathesis combined with environmental factors stemming from excessive salt consumption and stress. Cause of secondary hypertension is clearly defined and stems from conditions including renal hypertension, endocrine hypertension, cardiovascular hypertension, and neurogenic hypertension (Kaplan and Victor, 2010).

Two experiments were conducted as part of this research to clarify whether or not the consumption of goat meat dishes is in fact a contributing factor in hypertension. In experiment 1 , the effects on blood pressure in rats of salt and medicinal flavoring (mugwort leaves) used in goat meat dishes were investigated. In experiment 2 , the effects on blood pressure of a reduction of salt in diet were investigated.

\section{MATERIALS AND METHODS}

\section{Experiment 1: The effect of goat meat consumption on blood pressure of rats}

Animals: In the experiment, 24 Dahl/Iwai rats (4 week old males weighing $98.7 \pm 1.4 \mathrm{~g}$ ) were bought from Japan SLC, Inc, Shizuoka. The animals were housed in individual metal cages $(37 \mathrm{~cm}[\mathrm{~L}] \times 25 \mathrm{~cm}[\mathrm{~W}] \times 20 \mathrm{~cm}[\mathrm{H}])$ in a room with a temperature of $23.7 \pm 0.7^{\circ} \mathrm{C}$, relative humidity of $77.3 \pm 5.4 \%$, and were exposed to $12 \mathrm{~h}$ light/dark cycles (light cycle $6: 00$ to $18: 00$ ). A ten week acclimatization period in this environment was allowed prior to the start of the experiment under the same conditions. During the acclimatization period, the animals were fed a normal rat diet of 10 to $13 \mathrm{~g}$ of pellets (CE-2, CLEA Japan, Inc. Tokyo) and were given free access to water. During this period, each animal was subjected to $5 \mathrm{~min}$ of handling each morning to familiarize them with being held. To allow the animals to become used to blood pressure measurement procedures, practice measurements were carried out twice a week. Dhal/Iwai rats are laboratory animals bred with reduced renal filtration function in order to make them suitable subjects for research on human hypertension.

Experimental design: On the main island of Okinawa, goat meat soup is flavored with salt and mugwort. In experiment 1 , in order to clarify whether or not the consumption of goat meat alone was responsible for blood pressure increases, rats were fed on a diet of goat meat and their blood pressures were compared to a control group that was fed on chicken. Secondly, to clarify the blood pressure effects of the salt and mugwort used in flavoring goat meat soup, the blood pressre of rats fed on a diet of goat meat containing $3 \%$ to $4 \%$ sodium chloride, and goat meat containing $3 \%$ to $4 \%$ sodium chloride and $5 \%$ mugwort was compared to the blood pressure of rats fed on a diet of goat meat contained $0.3 \%$ sodium chloride.

Four groups of 6 rats (total 24 rats, 15 weeks old, body weight $309.3 \pm 11.1 \mathrm{~g}$ ), all sufficiently used to handling and blood pressure measurement processes, were used (control group, goat meat group, goat meat/salt group, mugwort/salt group) in order to investigate the effects of goat meat consumption on blood pressure over a 14 week period. The groups were each fed specific diets (control group (CP) formulated feed containing $20 \%$ chicken, $0.3 \%$ sodium chloride; goat meat group (GM), formulated feed containing $20 \%$ goat meat, $0.3 \%$ sodium chloride; goat meat/salt group (GS), formulated feed containing $20 \%$ goat meat, $3.0 \%$ sodium chloride; mugwort/salt group (GY), formulated feed containing $20 \%$ goat meat, $3.0 \%$ sodium chloride, and $5 \%$ freeze dried mugwort powder (Tables 2 and 3). Each animal was observed to consume all of the feed supplied to it within the day of receiving it. All the groups were given the same amount of feed. Feed intake was measured at 9 am 
each day. Water intake was measured 3 times a week at 9 am. Blood pressure, heart rate, and body weight were measured once a week. Body weight was measured in the morning at 9 am while blood pressure and heart rate were measured between 13:00 to 15:00. Feed and water intake values were obtained by subtracting remaining feed and water from the amount first supplied. Body weight was measured by placing the rat into a cardboard cylinder to prevent movement. The cylinder was then weighed using a platform scale (BJ1500, Zaryutoryus.Japan Inc. Tokyo). Blood pressure and heart rate were measured using the Tailcuff method which utilizes a plethysmographic sphyigmomanometer (BP-98A, Softron, Tokyo) and allows for measurements to be carried out without the need for anesthetic. The rats were placed in a warmer (UR-1000, Ueda-seisakusho, Tokyo) one at a time and kept there for approximately $10 \mathrm{~min}$ at $37^{\circ} \mathrm{C}$. The rats were then transferred to a metallic conical holder. A cuff probe was then attached to the tail of the animal and systolic blood pressure, diastolic blood pressure, and heart rate were measured. Two sizes of cuff probes were used (RCP-2, RCP-3, Softron, Tokyo) as the animals grew and matured. Blood pressure and heart rate for each animal was measured 3 times and the value recorded was the average of the three measurements. In order to measure the blood pressure of the rats during a state of rest, a cardboard cover was made to shut out the light and induce a resting state.

Production of experimental diets:

i) Chemical analysis of chicken and goat meat: Chicken (broiler breast from 42 day old chickens - Chuo Shokuhin Kako, Okinawa) and goat meat (4 year old male goats University of the Ryukyus, Faculty of Agriculture) were minced to use as feed ingredients for the experiment. Following this process, the crude protein, crude fat and crude ash of the meats was measured (Table 1).

ii) Formulation of experimental diets: The feed was formulated based on AIN-93 purified diets for laboratory rodent (Reeves et al., 1993; American Institute of Nutrition). Due to the mixing process, when compared to goat meat, the total crude fat in chicken was lower in the feed for the $\mathrm{CP}$ group (chicken 9.32, goat meat $31.20 \mathrm{~g} / 100 \mathrm{~g} \mathrm{DM}$ ). To correct this, lard was added to the feed for the CP group in order to make the fat content in the feed for all groups approximately the same. Due to the mixing process, when compared to chicken meat, the total crude protein in goat

Table 1. Chemical composition of chicken and goat meat

\begin{tabular}{lcc}
\hline Chemical composition $(\%)$ & Chicken & Goat meat \\
\hline Dry matter & 24.6 & 32.4 \\
Crude protein & 86.4 & 64.3 \\
Ether extract & 9.3 & 31.2 \\
Ash & 4.0 & 3.1 \\
\hline
\end{tabular}

Crude protein, ether extract and ash are indicated by \% per DM. meat was lower in the feed formulated for the three goat meat groups (chicken 86.43, goat meat $64.30 \mathrm{~g} / 100 \mathrm{~g} \mathrm{DM}$ ). To correct this, casein was added to the feed for these three groups in order to make the protein content in the feed for all groups approximately the same. The salt content in the $\mathrm{CP}$ group and GM group was virtually the same as compound feeds (CE-2, CLEA Japan, Tokyo). In contrast, salt was added to the feed for the GS and GY groups in order to make the salt content the same as the goat meat soup eaten in Okinawa. The GY group was created because mugwort is added to goat meat soup as a medicinal seasoning. Freeze dried mugwort powder was added to the feed for the GY group (5\%) resulting in a higher total crude fiber content in the group's feed. Cellulose powder was added to the feed of the other groups in order to make the crude fiber content of the feeds for all groups virtually the same. All other ingredients in the feeds for all the groups were the same.

iii) Production of experimental diets: Firstly, cornstarch, casein, dextrinized cornstarch, sucrose, mineral mix, and vitamin mix (Oriental koubo kogyou, Tokyo) were measured out and mixed together in a mixer (PMT-18, Mazelar, Nigata). Secondly, minced chicken was added to a pot with distilled water $(500 \mathrm{~mL}$ per $\mathrm{kg}$ of feed $)$ and salt and brought to the boil. Lard, antioxidant, vitamin E ( $0.15 \mathrm{~g}$ per $\mathrm{kg}$ of feed) was then dissolved into the feed. The mixture was then allowed to cool. Thirdly, the chicken meat mixture was added to the earlier prepared ingredients and blended to form a paste. For the feed given to the GM group, the minced chicken was substituted with goat meat (4 year old Japanese Saanen and Nubian crossbreed). An additional 3\% of salt was added to the goat meat feed used for the GS group. Freeze dried mugwort powder with added essential oil (twice the volume of the mugwort powder) and 3\% salt was added to the feed of the GY group. The feed paste was then formed into pellets using an extruder (TA-02 Takashima Shoten, Kanagawa). Following this process, the pellets were placed in a circulation drier (PH-201, Espec, Osaka) at a temperature of $70^{\circ} \mathrm{C}$ for $48 \mathrm{~h}$ (Tables 1 and 2). The mugwort powder was prepared using the following method. The leaves of Okinawan mugwort grown outdoors at the University of the Ryukyus Faculty of Agriculture, were crushed using a crushing machine (MKCAIO-20JF, Zouko, Saitama). The crushed leaves were then placed in a vacuum freeze drier (TF10-50ATM, Takara-seisakusho, Tokyo) for approximately $72 \mathrm{~h}$. During the drying process, the essential oils, thought to be functional components of the mugwort, were collected. The day before formulation the freeze dried mugwort was finely powdered using a mixer with a mill (BM-FT08, Zojirushi Corporation, Tokyo).

Chemical analysis of feeds and meats:

i) Chemical analysis of diets: The chemical composition analysis of the feed for each group is shown in Table 3 . The 
Table 2. Ingredient composition of experimental diets fed to animals in control (CP), goat meat (GM), goat meat with salt (GS), and goat meat with salt and mugwort (GY) groups in experiment 1

\begin{tabular}{|c|c|c|c|c|}
\hline $\begin{array}{l}\text { Ingredients } \\
\text { (g/100 g DM diet) }\end{array}$ & $\mathrm{CP}$ & GM & GS & GY \\
\hline Cornstarch & 41.7 & 41.6 & 38.9 & 37.9 \\
\hline Chicken & 20.0 & 0.0 & 0.0 & 0.0 \\
\hline Goat meat & 0.0 & 20.0 & 20.0 & 20.0 \\
\hline Casein & 0.7 & 5.1 & 5.1 & 2.0 \\
\hline Dextrin & 13.2 & 13.2 & 13.2 & 13.2 \\
\hline Sucrose & 10.0 & 10.0 & 10.0 & 10.0 \\
\hline Lard & 4.4 & 0.0 & 0.0 & 0.0 \\
\hline Fiber & 5.0 & 5.0 & 5.0 & 4.1 \\
\hline Mugwort & 0.0 & 0.0 & 0.0 & 5.0 \\
\hline Mineral mix ${ }^{a}$ & 3.5 & 3.5 & 3.5 & 3.5 \\
\hline $\begin{array}{l}\text { Vitamin } \operatorname{mix}^{\mathrm{b}} \\
\text { (choline chloride) }\end{array}$ & 1.3 & 1.3 & 1.3 & 1.3 \\
\hline Sodium chloride & 0.3 & 0.3 & 3.0 & 3.0 \\
\hline Total & 100.0 & 100.0 & 100.0 & 100.0 \\
\hline \multicolumn{5}{|c|}{$\begin{array}{l}\text { aineral mix (mg/kg) contained Ca 5,000.0; Pi 1,561.0; K 3,600.0; S } \\
\text { 300.0; Na 1,019.0; Cl 1,571.0; Mg 507.0; Fe 35.0; Zn 30.0; Mn 10.0; Cu } \\
\text { 6.0; I 0.2; Mo 0.15; Se 0.15. } \\
\text { bitamin mix (IU/kg) contained Nicotinic acid 30; Pantothenate 15; } \\
\text { Pyridoxine 6; Thiamin 5; Riboflavin 6; Folic acid 2; Vitamin K 750; D- } \\
\text { Biotin 200; Vitamin } \mathrm{B}_{12} \text { 25; Vitamin A 4,000; Vitamin } \mathrm{D}_{3} 1,000 \text {; Vitamin } \\
\text { E 75. }\end{array}$} \\
\hline
\end{tabular}

pellet feed was roughly crushed with a mixer/mill and then using a Wiley mill (1029-A, Yoshida-seisakusho, Tokyo) the crushed pellets were ground so as to pass through a 1 $\mathrm{mm}$ screen. The chemical composition of the feed was quantified using methods specified in AOAC (1990).

ii) Chemical analysis of meats: The chemical composition of meat is shown in Table 1. The chemical composition analysis (water content, crude protein, crude fat, and crude ash) on meat was conducted after thawing. Water content and crude fat analysis was carried out using the same method as other feed component analysis.

\section{Experiment 2: The effects on blood pressure of a reduction of salt in diet}

Experimental design: Experiment 2 was conducted as soon as experiment 1 was concluded. In experiment 2 , in order to clarify whether the increased blood pressure in the GS group and the GY group rats from experiment 1 was caused by excessive salt intake, the salt content in the feed of the GS group and the GY group was reduced.

The 24 Dahl/Iwai rats (29 months old, body weight $419.3 \pm 19.6 \mathrm{~g}$, male) used in experiment 1 were divided into 4 groups, the CP, GM, GS, and GY groups. In experiment 2, the salt content in the feed of the GS group and the GY group was reduced from $4 \%$ to $0.3 \%$ (Table 11). The experiment was conducted 4 weeks after the conclusion of experiment 1 . During the 4 weeks between experiments,
Table 3. Chemical composition of experimental diets fed to animals in control (CP), goat meat (GM), goat meat with salt (GS), and goat meat with salt and mugwort (GY) groups in experiment 1

\begin{tabular}{lcccc}
\hline $\begin{array}{l}\text { Chemical composition } \\
\text { (\% of DM) }\end{array}$ & CP & GM & GS & GY \\
\hline Dry matter & 91.0 & 91.7 & 90.7 & 90.1 \\
Crude protein & 17.8 & 15.5 & 16.6 & 15.4 \\
Ether extract & 4.9 & 6.0 & 5.9 & 6.1 \\
Crude fiber & 3.5 & 3.5 & 3.8 & 4.3 \\
Ash & 3.6 & 3.4 & 6.4 & 7.0 \\
Nnitrogen free extract & 70.2 & 71.6 & 67.5 & 67.2 \\
Na (mg/100 g DM) & 0.38 & 0.43 & 1.97 & 2.31 \\
$\mathrm{~K}(\mathrm{mg} / 100$ g DM) & 0.90 & 0.73 & 1.07 & 1.20 \\
$\mathrm{GE} \mathrm{(kcal/100} \mathrm{g} \mathrm{DM)}{ }^{\mathrm{a}}$ & 468.7 & 467.3 & 457.8 & 454.3 \\
\hline${ }^{\mathrm{a}} \mathrm{GE}=$ Gross energy. & & & &
\end{tabular}

water intake, feed intake, body weight, heart rate, and blood pressure were measured the same as in experiment 1 . Following the completion of the experiment 2, all the animals (33 months old) were subjected to an intraperitoneal injection of pentobarbital sodium saline solution and were put down under general anesthesia.

Once the animals were put under anesthesia, blood was sampled from the hepatic portal vein. Then, blood parameters related to hepatic and renal functions were measured, and the wet weight of the animal's organs was recorded.

Necropsy, blood sampling, and internal organ weight measurements: Following a $15 \mathrm{~h}$ fasting period, an intraperitoneal injection of pentobarbital sodium saline solution $(5 \mathrm{mg} / \mathrm{mL}$ of pentobarbital sodium diluted in saline) was administered $(4 \mathrm{mg} / 0.8 \mathrm{~mL} /$ bodyweight $100 \mathrm{~g})$ and the animals were placed under general anesthesia. After $10 \mathrm{~min}$, the animals were fixed to a plate and given a supplemental ether anesthesia while their abdomen was opened using a pair of scissors. After the ventral organs were pushed aside using cotton to expose the veins, the hepatic portal vein was identified and approximately 5 to 8 $\mathrm{mL}$ of blood was collected. The blood sample was collected with a heparinized syringe and placed on ice in a test tube for storage.

After the blood samples were collected, the chest cavity was opened using scissors and the heart was enucleated. The bilateral kidneys, bilateral adrenal glands, liver, spleen, and bilateral testes were also removed. The brain was also removed. Following removal, the organs were weighed and then placed in a $10 \%$ formalin-saline solution for storage.

All experimental procedures were approved by the Animal Experimental Ethics Committee of the University of the Ryukyus and were in compliance with the Japanese code of practice for the care and use of animals for scientific purposes. 
Chemical composition of diets: The chemical composition of the feed was carried out using the same methods as in experiment 1 (Table 6).

\section{Biochemical analysis of blood samples}

Erythrocyte numbers in the blood, diluted in a Hayem's reagent solution, were counted under a microscope using a Thoma hemocytometer (kayagaki-seisakusho, Tokyo). Leucocyte numbers in the blood, diluted in a Türk's reagent solution, were counted under a microscope using a Thoma hemocytometer (kayagaki-seisakusho, Tokyo). Blood samples were placed in capillary tubes and centrifuged using a hematocrit centrifuge (HC-12A, Tomy Seiko, Tokyo; $5 \mathrm{~min}, 12,851 \times g$ ) to determine hematocrit using a hematocrit reader (Tomy Seiko, Tokyo). Plasma total protein concentration and osmolality were measured using a refractometer (Atago, Tokyo) and an osmometer (OM-6010, Kyoto Daiichi Kagaku, Kyoto), respectively. The plasma concentrations of total hemoglobin, albumin, creatinine, urea-N, total bilirubin, glucose, glutamate-oxaloacetate transaminase (GOT), glutamate-pyruvate transaminase (GPT), $\mathrm{Ca}^{2+}$, inorganic phosphorus, $\mathrm{Mg}$, were measured using a Spotchem EZ (SP-4430, Arkray, Kyoto). The plasma concentrations of $\mathrm{Na}, \mathrm{K}$ and $\mathrm{Cl}$ were measured using a Spotchem EL (SE-1520, Arkray, Kyoto). Total cholesterol, triglycerides, free fatty acids, phospholipids, HDL cholesterol, and LDL cholesterol concentrations in the plasma were measured based on the spectrocolorimetric method using a measurement kit (Wakou junyaku kogyou, Osaka). Plasma LDL cholesterol concentration was calculated by subtracting HDL cholesterol and 1/5 plasma triglycerides from total cholesterol.

\section{Statistical analysis}

Measured values are shown for each week as a mean value of the 6 animals in the group. A one-way analysis of variance and a subsequent Duncan's multiple range test were used to compare the daily feed intake, water intake, body weight, blood pressure, blood parameters and organ's wet weight between control (PC) and treatments (GM, GS, GY). For statistical analysis, GLM procedure (SAS, 1990) was used.

All data were analyzed using the following model:

$$
\mathrm{Y}_{\mathrm{ij}}=\mu+\mathrm{T}_{\mathrm{i}}+\varepsilon_{\mathrm{ij}}
$$

Where $Y_{i j}=$ the measured variable; $\mu=$ the overall mean; $\mathrm{T}_{\mathrm{i}}=$ the effect of the $\mathrm{i}^{\text {th }}$ treatment; $\varepsilon_{\mathrm{ij}}=$ the random error effect.

\section{RESULTS}

Experiment 1: The effect of goat meat consumption on

\section{blood pressure of rats}

Chemical composition of chicken, goat meat and experimental diets: While goat meat was higher in dry matter and crude fat than chicken, it was lower in crude protein (Table 1). The crude protein content of the feed used was similar to the CLEA Rodent Diet C7 that is the main constituent of soybean meal (CLEA Japan Inc, Tokyo). It was however higher in crude fat and NFE (nitrogen free extracts) and therefore the feed was higher in energy (approx. $100 \mathrm{kcal} / 100 \mathrm{~g} \mathrm{DM}$ ) (Table 3). The components and energy content of the feed used for the GM group was virtually the same as the feed for the CP group. In contrast, the crude ash and $\mathrm{Na}$ content in the feeds of the GS group, and the GY group was higher than the feed used for the CP group and the GM group. The crude fiber content of the feed for the GY group tended to be higher than the other three groups.

Effect of goat meat consumption on feed intake, water intake, and daily body weight gains: Changes in feed intake are illustrated in Table 4. The four types of diets used in the experiment were palatable for the animals. The groups were given an amount of feed that could be consumed within a day $(16.0 \pm 0.1 \mathrm{~g} / \mathrm{head} / \mathrm{d})$. There was no significant difference in the feed intake among the GM, GS, GY, and $\mathrm{CP}$ groups. Water intake changes are shown in Figure 1. The water intake in animals in the GM group (22.1 \pm 1.7 $\mathrm{g} / \mathrm{head} / \mathrm{d}, \mathrm{n}=6$ ) over the 14 week period was virtually equal to the CP group $(21.0 \pm 1.3 \mathrm{~g} / \mathrm{head} / \mathrm{d}, \mathrm{n}=6)$. In contrast, the water intake observed in the GS group and the GY group

Table 4. Feed intake in control (CP), goat meat (GM), goat meat with salt (GS), and goat meat with salt and mugwort (GY) groups in experiment 1

\begin{tabular}{|c|c|c|c|c|c|}
\hline \multirow{2}{*}{$\begin{array}{l}\text { Age } \\
\text { (weeks) }\end{array}$} & \multicolumn{4}{|c|}{ Groups } & \multirow{2}{*}{ SEM } \\
\hline & $\mathrm{CP}$ & GM & GS & GY & \\
\hline & \multicolumn{4}{|c|}{ - } & \\
\hline 15 & 16.45 & 16.45 & 16.67 & 16.48 & 0.088 \\
\hline 16 & 16.00 & 16.00 & 16.00 & 15.86 & 0.075 \\
\hline 17 & 14.00 & 14.00 & 14.00 & 14.00 & 0.000 \\
\hline 18 & 16.00 & 16.00 & 16.00 & 16.00 & 0.000 \\
\hline 19 & 16.00 & 15.62 & 16.00 & 15.77 & 0.201 \\
\hline 20 & 15.92 & 15.59 & 16.00 & 15.67 & 0.199 \\
\hline 21 & 15.85 & 15.78 & 16.00 & 15.68 & 0.179 \\
\hline 22 & 15.90 & 16.00 & 16.00 & 15.89 & 0.066 \\
\hline 23 & 16.54 & 16.65 & 16.86 & 16.36 & 0.272 \\
\hline 24 & 16.00 & 16.12 & 16.57 & 16.43 & 0.229 \\
\hline 25 & 15.85 & 15.79 & 16.00 & 15.91 & 0.081 \\
\hline 26 & 15.84 & 15.77 & 16.00 & 15.77 & 0.171 \\
\hline 27 & 15.88 & 15.73 & 16.00 & 15.85 & 0.106 \\
\hline 28 & 15.92 & 15.86 & 16.00 & 16.00 & 0.055 \\
\hline 29 & 15.91 & 15.97 & 16.00 & 15.96 & 0.041 \\
\hline
\end{tabular}

Values are indicated by mean \pm SEM of six animals in control (CP), goat meat (GM), goat meat with salt (GS), and goat meat with salt and mugwort (GY) groups. 

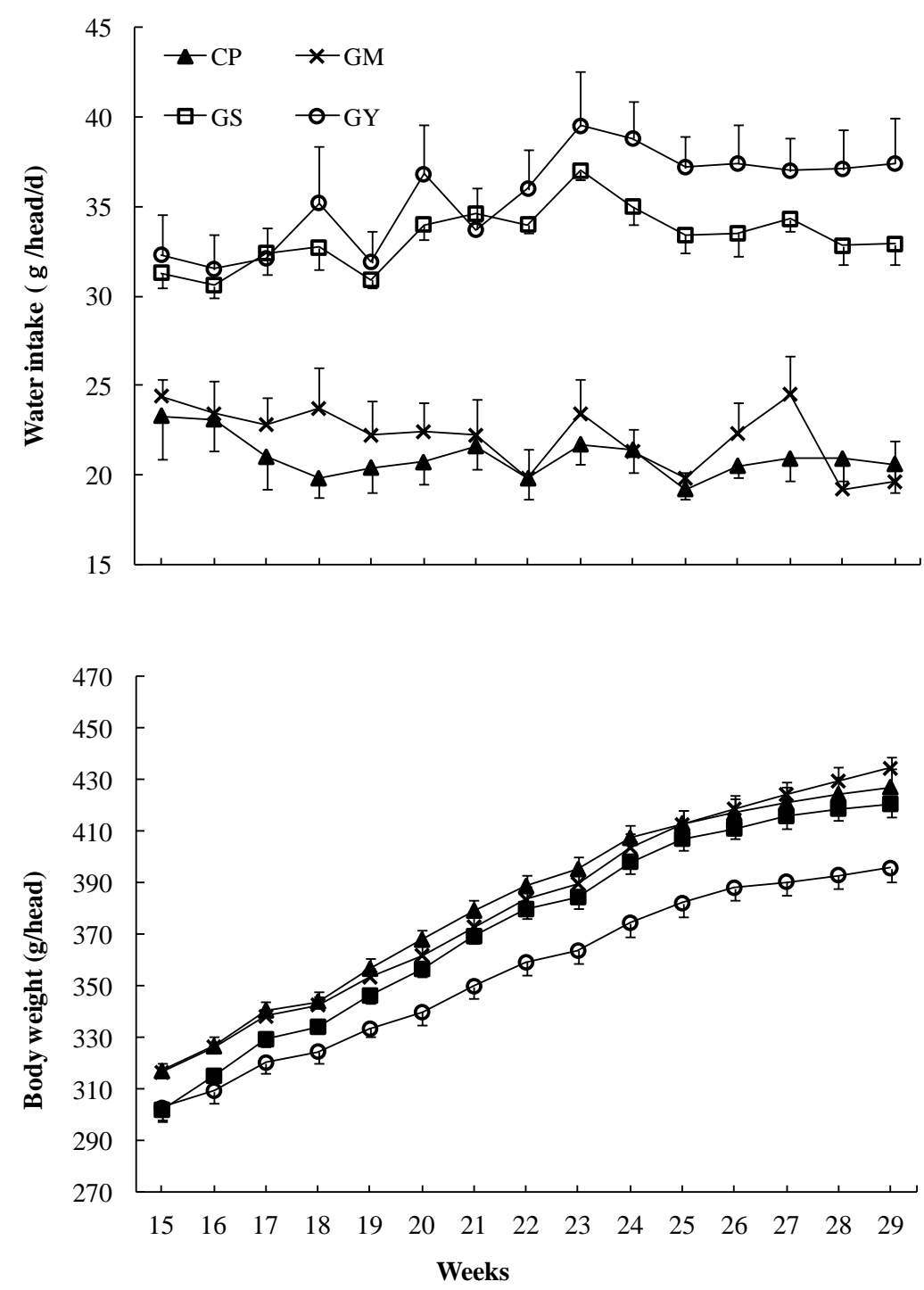

Figure 1. Effects of goat meat consumption on water intake and body weight. Values are indicated by mean $\pm \mathrm{SE}$ of six animals in control $(\mathrm{CP})$, goat meat $(\mathrm{GM})$, goat meat with salt (GS), and goat meat with salt and mugwort (GY) groups. $\square$, ○: Significance from $\mathrm{CP}$ group $(\mathrm{p}<0.01)$.

$(33.3 \pm 1.0, \quad 35.6 \pm 2.3 \mathrm{~g} / \mathrm{head} / \mathrm{d}, \mathrm{n}=6)$ was significantly higher $(\mathrm{p}<0.01)$ than both the GM group and the CP group $(21.0 \pm 1.3 \mathrm{~g} / \mathrm{head} / \mathrm{d}, \mathrm{n}=6)$. Changes in body weight are shown in Figure 1. Upon commencement of the experiment, the 15 week old animals were all of a similar weight (CP $316.7 \pm 3.0 \mathrm{~g} / \mathrm{head}, \mathrm{n}=6$; GM $316.2 \pm 1.8 \mathrm{~g} / \mathrm{head}, \mathrm{n}=6$; GS $301.7 \pm 4.3 \mathrm{~g} / \mathrm{head}, \mathrm{n}=6$; GY $302.7 \pm 4.8 \mathrm{~g} / \mathrm{head}, \mathrm{n}=6$ ). Upon conclusion of experiment 1 , the weights of the 29 week old animals in the CP $(427.0 \pm 7.1 \mathrm{~g} / \mathrm{head}), \mathrm{GM}$ $(434.3 \pm 4.6 \mathrm{~g} / \mathrm{head})$, and GS $(420.5 \pm 5.0 \mathrm{~g} / \mathrm{head})$ were all very similar. The weights of the animals in GY however were significantly $(\mathrm{p}<0.01)$ lighter $(395.6 \pm 5.2 \mathrm{~g} / \mathrm{head})$. The cumulative body weight gain over the course of the 14 week experiment was similar among the CP group $(110.3 \pm 5.4$ $\mathrm{g} /$ head/14 weeks, $\mathrm{n}=6)$, the GM group $(118.1 \pm 3.7$ $\mathrm{g} / \mathrm{head} / 14$ weeks, $\mathrm{n}=6)$, and the GS group $(118.8 \pm 3.9$ $\mathrm{g} / \mathrm{head} / 14$ weeks, $\mathrm{n}=6$ ). The cumulative weight gain of the GY group however was significantly lower $(p<0.01)$ $(92.9 \pm 0.9 \mathrm{~g} / \mathrm{head} / 14$ weeks, $\mathrm{n}=6)$ than the $\mathrm{CP}$ group.

Effect of goat meat consumption on heart rate and blood pressure: Table 5 shows the heart rate. There was no significant difference in the heart rate among the four experimental groups (CP 385.1 \pm 8.1 beats/min, $\mathrm{n}=6$; $\mathrm{GM}$ group $377.2 \pm 10.7$ beats/min, $\mathrm{n}=6$; GS group $373.9 \pm 9.2$ beats/min, $\mathrm{n}=6$, and $\mathrm{GY}$ group $367.0 \pm 8.8$ beats/min, $\mathrm{n}=6$ ). Figure 2 shows systolic blood pressure and diastolic blood pressure. In the GS group and GY group, from age 20 weeks to 29 weeks, salt content in the feed was increased from $3 \%$ to $4 \%$. The systolic blood pressure of all the animals at 15 weeks of age, when the experiment was 
Table 5. Heart rate in control (CP), goat meat (GM), goat meat with salt (GS), and goat meat with salt and mugwort (GY) groups in experiment 1

\begin{tabular}{lllllr}
\hline Age (weeks) & \multicolumn{2}{c}{ Groups } & \multicolumn{2}{c}{ SEM } \\
\cline { 2 - 4 } & CP & GM & GS & GY \\
15 & 396 & 390 & 389 & 384 & 10.7 \\
16 & 396 & 404 & 390 & 382 & 8.9 \\
17 & 390 & 378 & 392 & 371 & 10.1 \\
18 & 385 & 371 & 369 & 367 & 9.4 \\
19 & 386 & 383 & 367 & 367 & 9.5 \\
20 & 395 & 383 & 380 & 377 & 9.5 \\
21 & $391^{\mathrm{a}}$ & $377^{\mathrm{ab}}$ & $363^{\mathrm{b}}$ & $359^{\mathrm{b}}$ & 6.0 \\
22 & 383 & 378 & 370 & 372 & 9.3 \\
23 & 399 & 358 & 373 & 367 & 9.7 \\
24 & 375 & 363 & 358 & 352 & 9.2 \\
25 & 372 & 378 & 372 & 363 & 7.5 \\
26 & 379 & 362 & 365 & 361 & 8.1 \\
27 & 375 & 374 & 368 & 362 & 9.2 \\
29 & 375 & 373 & 377 & 350 & 11.1 \\
\hline
\end{tabular}

Values are indicated by mean \pm SEM of six animals in control (CP), goat meat (GM), goat meat with salt (GS), and goat meat with salt and mugwort (GY) groups.

${ }_{a, b}$ Means in the same row bearing different superscripts are significantly different $(\mathrm{p}<0.01)$.
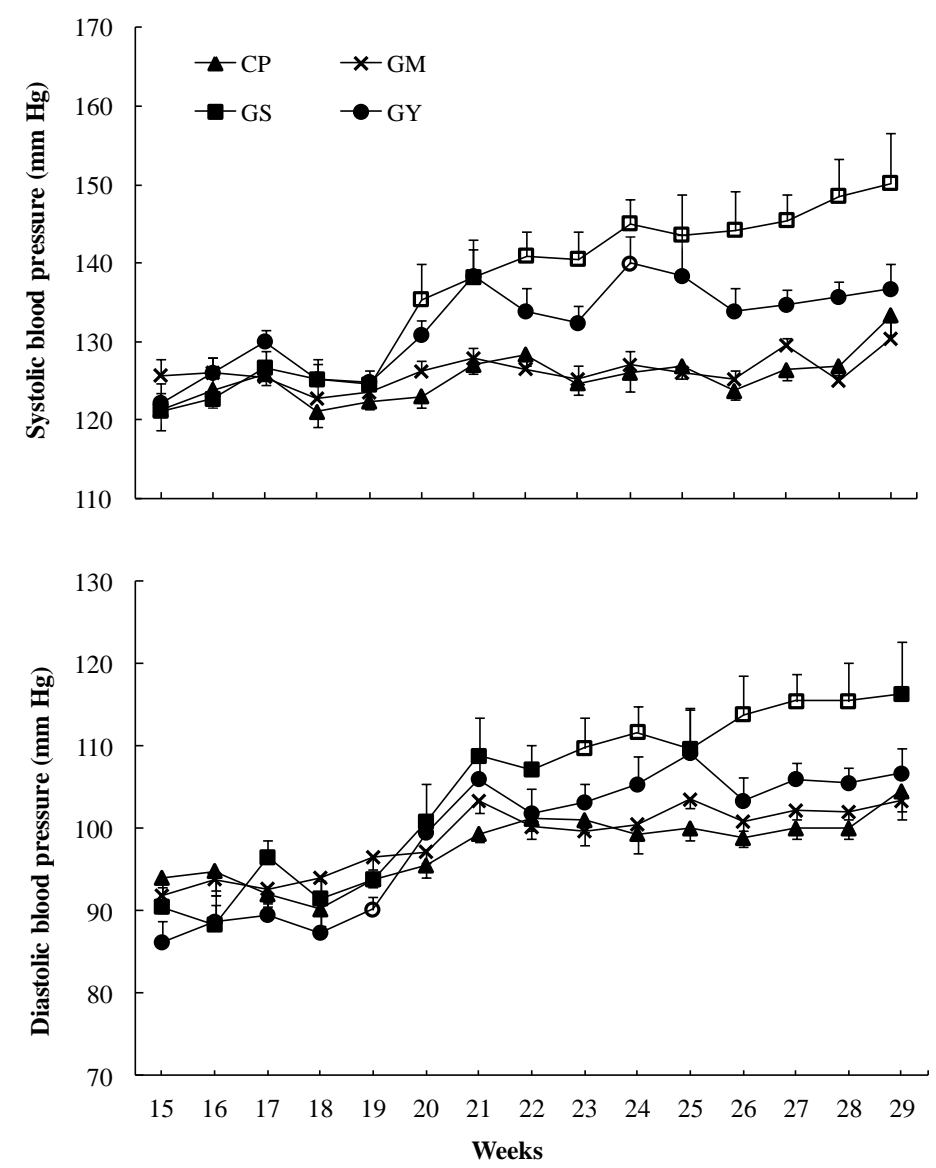

Figure 2. Effects of goat meat consumption on systolic blood pressure and diastolic blood pressure. Values are indicated by mean \pm SE of six animals in control (CP), goat meat (GM), goat meat with salt (GS), and goat meat with salt and mugwort (GY) groups. $\square$, ○: Significance from CP group $(\mathrm{p}<0.01)$. 
begun, was $121.3 \pm 2.6$ (CP group), 125.7 \pm 2.1 (GM group), 121.2 \pm 2.3 (GS group), and 122.2 $\pm 2.6 \mathrm{~mm} \mathrm{Hg}$ (GY group). Systolic blood pressure in the animals of the GM group (126.2 \pm 1.6$)$ over the 14 week experiment was similar to the CP group (125.4 \pm 2.0$)$. In contrast, systolic blood pressure in the GS and GY groups increased after the animals reached 20 weeks of age. Compared to the CP group $(127.0 \pm 1.9 \mathrm{~mm} \mathrm{Hg})$ and the GM group $(126.8 \pm 1.5 \mathrm{~mm} \mathrm{Hg})$, the systolic blood pressure of the GS group $(144.9 \pm 1.5 \mathrm{~mm}$ $\mathrm{Hg}$ ) was significantly higher $(\mathrm{p}<0.01)$ after 20 weeks of age. The systolic blood pressure of the GY group (135.7 \pm 3.1 $\mathrm{mm} \mathrm{Hg}$ ) tended to be higher than the CP and GM groups after 22 weeks of age. When compared to the GS group, the systolic blood pressure of the GY group tended to be lower after 22 weeks of age. The diastolic blood pressure of all the animals at 15 weeks of age, when the experiment was begun, was 94.0 \pm 2.6 (CP group), 91.8 \pm 2.5 (GM group), $90.5 \pm 1.7$ (GS group), 86.2 $\pm 1.7 \mathrm{~mm} \mathrm{Hg}$ (GY group). The diastolic blood pressure of the animals in all the groups increased after 19 weeks of age. The diastolic blood pressure of the animals in the GM group $(98.8 \pm 2.3 \mathrm{~mm} \mathrm{Hg}$ )

Table 6. Ingredients and chemical composition of experimental diets fed to animals in control (CP), goat meat (GM), goat meat with salt (GS), and goat meat with salt and mugwort (GY) groups in experiment 2

\begin{tabular}{|c|c|c|c|c|}
\hline $\begin{array}{l}\text { Ingredients } \\
\text { (g/100 g DM diet) }\end{array}$ & $\mathrm{CP}$ & GM & GS & GY \\
\hline Cornstarch & 41.7 & 41.6 & 41.6 & 40.6 \\
\hline Chicken & 20.0 & 0.0 & 0.0 & 0.0 \\
\hline Goat meat & 0.0 & 20.0 & 20.0 & 20.0 \\
\hline Casein & 0.7 & 5.1 & 5.1 & 2.0 \\
\hline Dextrin & 13.2 & 13.2 & 13.2 & 13.2 \\
\hline Sucrose & 10.0 & 10.0 & 10.0 & 10.0 \\
\hline Lard & 4.4 & 0.0 & 0.0 & 0.0 \\
\hline Fiber & 5.0 & 5.0 & 5.0 & 4.1 \\
\hline Mugwort & 0.0 & 0.0 & 0.0 & 5.0 \\
\hline Mineral mix ${ }^{a}$ & 3.5 & 3.5 & 3.5 & 3.5 \\
\hline $\begin{array}{l}\text { Vitamin } \operatorname{mix}^{\mathrm{b}} \\
\text { (choline chloride) }\end{array}$ & 1.3 & 1.3 & 1.3 & 1.3 \\
\hline Sodium chloride & 0.3 & 0.3 & 0.3 & 0.3 \\
\hline Total & 100.0 & 100.0 & 100.0 & 100.0 \\
\hline \multicolumn{5}{|c|}{ Chemical composition (\% of DM) } \\
\hline Dry matter & 91.0 & 91.7 & 91.7 & 90.8 \\
\hline Crude protein & 17.8 & 15.5 & 15.5 & 15.6 \\
\hline Ether extract & 4.9 & 6.0 & 6.0 & 6.9 \\
\hline Crude fiber & 3.5 & 3.5 & 3.5 & 3.8 \\
\hline Ash & 3.6 & 3.4 & 3.4 & 4.0 \\
\hline Nnitrogen free extract & 70.2 & 71.6 & 71.6 & 69.8 \\
\hline $\mathrm{Na}(\mathrm{mg} / 100 \mathrm{~g} \mathrm{DM})$ & 0.38 & 0.43 & 0.43 & 0.51 \\
\hline $\mathrm{K}(\mathrm{mg} / 100 \mathrm{~g} \mathrm{DM})$ & 0.90 & 0.73 & 0.73 & 1.09 \\
\hline $\mathrm{GE}(\mathrm{kcal} / 100 \mathrm{~g} \mathrm{DM})^{\mathrm{a}}$ & 468.7 & 467.3 & 467.3 & 475.9 \\
\hline
\end{tabular}

over the duration of the 14 week experiment was virtually the same as the CP group $(97.6 \pm 2.3 \mathrm{~mm} \mathrm{Hg})$. In contrast, after 23 weeks of age, the diastolic blood pressure of the GS group (113.2 $\pm 3.2 \mathrm{~mm} \mathrm{Hg}$ ), when compared to the $\mathrm{CP}$ group $(100.5 \pm 1.9 \mathrm{~mm} \mathrm{Hg})$ and the GM group $(101.7 \pm 1.7 \mathrm{~mm} \mathrm{Hg})$, was either significantly higher or showed a tendency to be higher. The diastolic blood pressure of the GM group $(105.6 \pm 2.7 \mathrm{~mm} \mathrm{Hg})$ after 23 weeks of age tended to be higher than the CP group and the GM group. The diastolic blood pressure of the GY group tended to be lower than the GS group after 22 weeks of age.

\section{Experiment 2: The effects on blood pressure of a reduction of salt in diet}

Chemical composition of diet: In experiment 2, the salt content in the feed of the GS and GY groups used in experiment 1 (at 29 weeks of age) was reduced from $4 \%$ to $0.3 \%$ (Table 6). The result was that the crude ash and sodium content in the GS and GY groups fell from $6.36 \%$, $6.98 \%, 1.79 \%, 2.31 \%$ in experiment 1 , to $3.40 \%, 3.96 \%$, $0.43 \%, 0.51 \%$ in experiment 2 (Tables 3 and 6). Because the crude fat and NFE content in the feed for the GS group and the GY group was high compared to experiment 1, the amount of energy contained in the feed also tended to be high in experiment.

Effect of salt reduction on feed intake, water intake, and daily body weight gains: Feed intake between 29 and 33 weeks of age in the animals in the GS group and the GY group was virtually the same as the CP group and GM group (Table 7). By contrast, water intake in the GS and GY groups at 29 weeks of age was significantly $(\mathrm{p}<0.05)$ higher that the CP and GM groups. However, after 30 weeks of age water intake in the GS and GY groups fell to levels observed in the CP and GM groups due to a reduction in the amount of salt in the feed (Figure 3). While body weight of the animals each week among the animals in the GS group was similar to the animals in the $\mathrm{CP}$ and GM groups, the animals in the GY group were significantly lighter $(\mathrm{p}<0.01)$. Body weight in all the groups increased with age (Figure 3 ).

Effect of salt reduction on heart rate and blood

Table 7. Feed intake in control (CP), goat meat (GM), goat meat with salt (GS), and goat meat with salt and mugwort (GY) groups in experiment 2

\begin{tabular}{|c|c|c|c|c|c|}
\hline \multirow{2}{*}{$\begin{array}{l}\text { Age } \\
\text { (weeks) }\end{array}$} & \multicolumn{4}{|c|}{ Groups } & \multirow{2}{*}{ SEM } \\
\hline & $\mathrm{CP}$ & GM & GS & GY & \\
\hline & \multicolumn{5}{|c|}{--------------------- g/head/d ------------------- } \\
\hline 29 & 15.91 & 15.97 & 16.00 & 15.96 & 0.041 \\
\hline 30 & 16.00 & 16.00 & 16.00 & 15.87 & 0.067 \\
\hline 31 & 15.98 & 15.86 & 16.00 & 15.93 & 0.075 \\
\hline 32 & 15.38 & 15.38 & 15.96 & 15.74 & 0.292 \\
\hline 33 & 15.78 & 15.63 & 15.81 & 15.81 & 0.165 \\
\hline
\end{tabular}

Values are indicated by mean \pm SEM of six animals. 

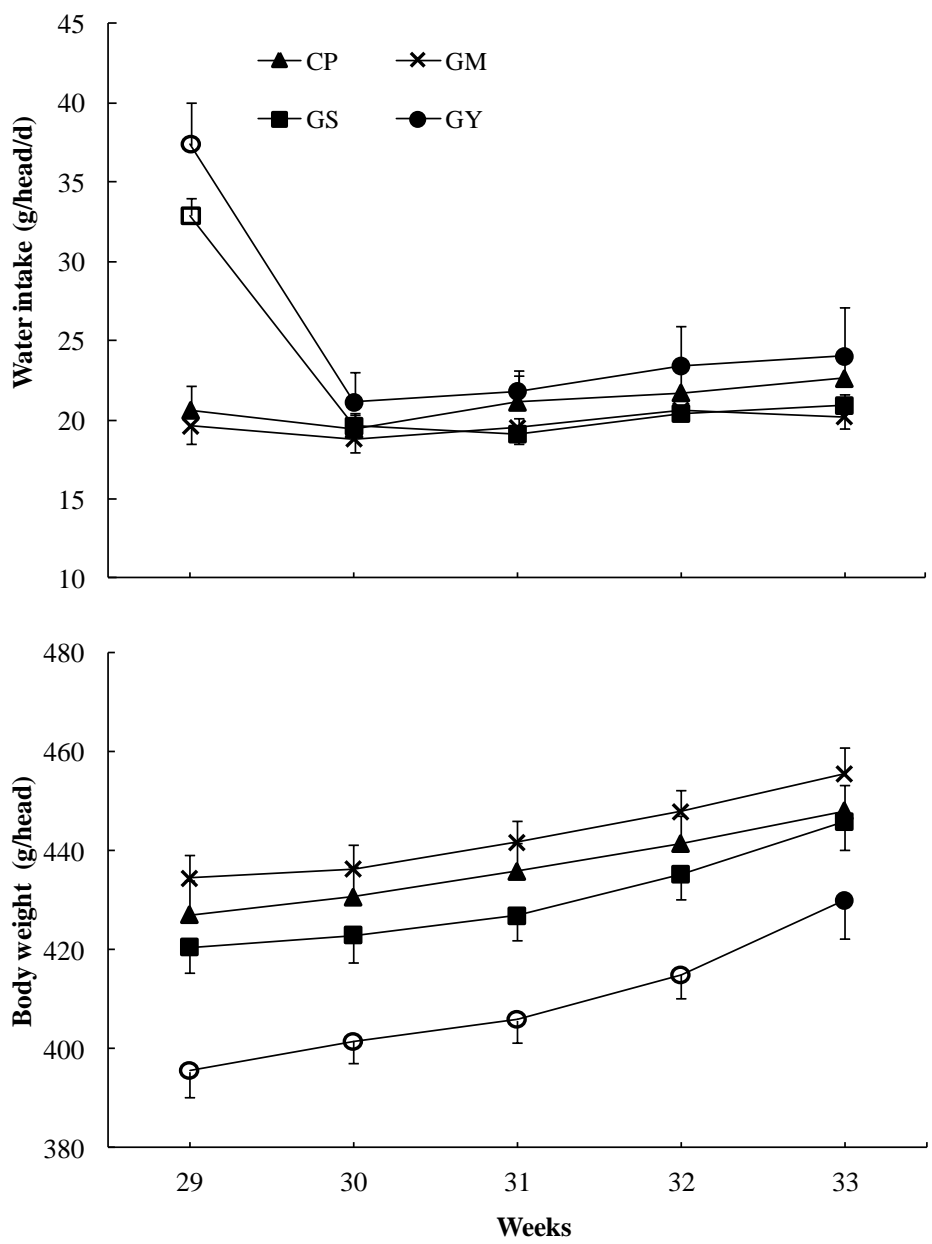

Figure 3. Effects of reduced-salt goat meat consumption on water intake and body weight. Values are indicated by mean \pm SE of six animals in control (CP), goat meat (GM), goat meat with salt (GS), and goat meat with salt and mugwort (GY) groups. $\square, \circ$ : Significance from $\mathrm{CP}$ group $(\mathrm{p}<0.01)$

pressure: Heart rate of the animals in the GS and GY groups was virtually the same as the animals in the CP and GM groups (Table 8). Systolic blood pressure at 29 weeks of age in the GS group was significantly higher $(\mathrm{p}<0.01)$ than the $\mathrm{CP}$ group and GM group. After 30 weeks of age however, the salt content in the feed was reduced from $4 \%$ to $0.3 \%$ which caused the systolic blood pressure of the GS group $(132.0 \pm 3.8 \mathrm{~mm} \mathrm{Hg})$ and $\mathrm{GY}$ group $(129.4 \pm 2.8 \mathrm{~mm} \mathrm{Hg})$ to

Table 8. Heart rate in control (CP), goat meat (GM), goat meat with salt (GS), and goat meat with salt and mugwort (GY) groups in experiment 2

\begin{tabular}{|c|c|c|c|c|c|}
\hline \multirow{2}{*}{$\begin{array}{l}\text { Age } \\
\text { (weeks) }\end{array}$} & \multicolumn{4}{|c|}{ Groups } & \multirow{2}{*}{ SEM } \\
\hline & $\mathrm{CP}$ & GM & GS & GY & \\
\hline & \multicolumn{5}{|c|}{ 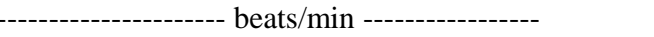 } \\
\hline 29 & 380 & 381 & 377 & 350 & 11.1 \\
\hline 30 & 371 & 362 & 379 & 365 & 7.2 \\
\hline 31 & 385 & 368 & 372 & 360 & 6.8 \\
\hline 32 & 379 & 374 & 365 & 366 & 7.1 \\
\hline 33 & 379 & 375 & 368 & 360 & 6.1 \\
\hline
\end{tabular}

Values are indicated by mean \pm SEM of six animals. fall to levels virtually the same as the CP group (127.5 \pm 1.0 $\mathrm{mm} \mathrm{Hg}$ ) and GM group (126.4 $\pm 1.4 \mathrm{~mm} \mathrm{Hg}$ ) (Figure 4). The diastolic blood pressure of the GS group at 29 weeks of age (experiment 1) tended to be higher than the other three groups. However, this trend disappeared after 30 weeks of age and similar diastolic blood pressure was observed in all groups (CP group 101.7 \pm 1.5 , GM group 102.0 \pm 1.0 , GS group 106.1 \pm 2.4 , GY group 103.7 $\pm 2.7 \mathrm{~mm} \mathrm{Hg}$ )(Figure 4).

Effect of goat meat consumption on blood parameters: Upon completion of the experiment at 33 weeks of age, hematocrit, erythrocyte count, and hemoglobin concentration of the animals in the GM, GS, and GY groups were similar to the animals in the $\mathrm{CP}$ group. However, the leucocyte count of the animals in the GY group was significantly higher $(\mathrm{p}<0.01)$ than the $\mathrm{CP}, \mathrm{GM}$, and GS groups (Table 10).

Compared to the CP group, total bilirubin level, GOT and GPT activity, all indicators of hepatic dysfunction, were significantly lower $(\mathrm{p}<0.01)$ in the GM, GS, and GY groups (Table 11). While the level of plasma albumin concentration 

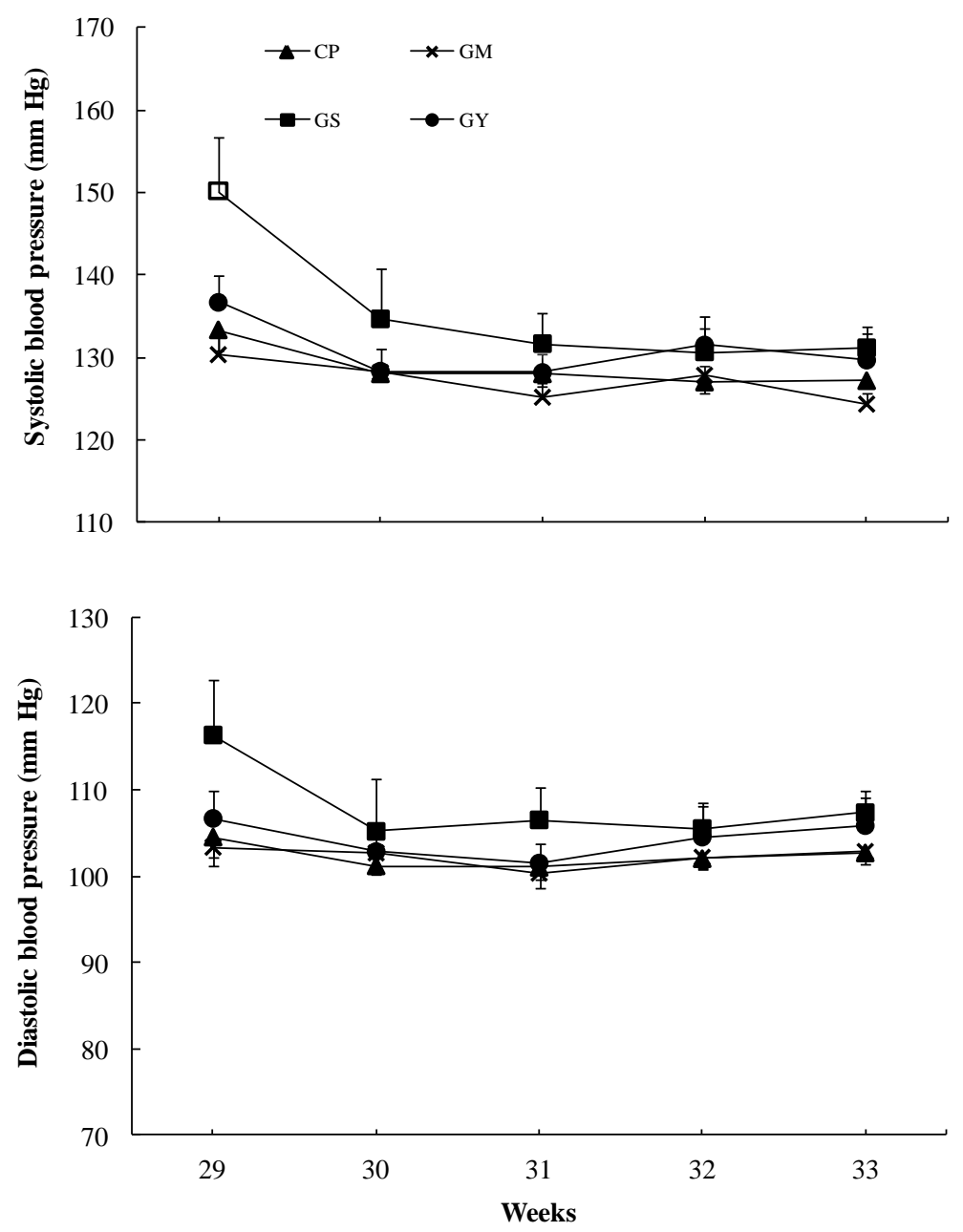

Figure 4. Effects of reduced-salt goat meat consumption on systolic blood pressure and diastolic blood pressure. Values are indicated by mean \pm SE of six animals in control (CP), goat meat (GM), goat meat with salt (GS), and goat meat with salt and mugwort (GY) groups. $\square$ : Significance from CP group $(\mathrm{p}<0.01)$.

in the GM group was significantly lower $(\mathrm{p}<0.01)$ than the CP group, it was similar to concentrations in the GS and GY groups. Plasma concentrations of triglycerides and LDL cholesterol in the 3 treatment groups were similar to the $\mathrm{CP}$ group. However, plasma concentrations of HDL cholesterol and phospholipids in the GY group were significantly higher $(\mathrm{p}<0.01)$ than the other groups.

Plasma creatinine concentration, an indicator of renal dysfunction, was lower in the GM and GY groups when compared to the CP group but similar to the control in the GY group (Table 12). Plasma urea nitrogen concentration in all three treatment groups was similar to the CP group. The plasma osmolality of the three treatment groups was significantly lower $(\mathrm{p}<0.01)$ or tended to be lower than the $\mathrm{CP}$ group. While the plasma inorganic phosphorus concentration in the GM group was significantly lower ( $<<0.01)$ than the CP group, the concentration in the GS and GY groups was virtually the same as the CP group. Plasma magnesium concentration in all three treatment groups was significantly lower $(\mathrm{p}<0.01)$ than the $\mathrm{CP}$ group.
Post experiment necropsy and internal organ's weight: The body weight of the animals in the GY group tended to be lower than the other three groups upon conclusion of the experiment at 33 weeks of age (Figure 3). The spleen weight of the animals in the GY group was significantly lighter $(\mathrm{p}<0.01)$ than the animals in the other groups (Table 9 ). There was no significant difference in the weight of any of the other internal organs of the animals from the three treatments when compared to the $\mathrm{CP}$ group. After macroscopic observation the organs from all the groups were determined to be normal.

\section{DISCUSSION}

The results of this experiment indicate that, as in the case of chicken consumption, there was no change in the blood pressure of rats that were fed daily on goat meat (34.8 $\mathrm{g}$ fresh meat $/ \mathrm{kg} \mathrm{BW}, 11.3 \mathrm{~g}$ dry matter/kg BW) over a period of three and a half months. The results also show that the consumption of high amounts of salt used in the goat 
Table 9. Organ's weight after the completion of experiment 2 in control (CP), goat meat (GM), goat meat with salt (GS), and goat meat with salt and mugwort (GY) groups

\begin{tabular}{|c|c|c|c|c|c|}
\hline \multirow{2}{*}{ Organs (g) } & \multicolumn{4}{|c|}{ Groups } & \multirow{2}{*}{ SEM } \\
\hline & $\mathrm{CP}$ & GM & GS & GY & \\
\hline Body weight (g) & 450.18 & 454.70 & 438.14 & 420.42 & 5.516 \\
\hline Brain & $\begin{array}{c}1.78 \\
\left(0.40^{\mathrm{a}}\right)\end{array}$ & $\begin{array}{c}1.84 \\
\left(0.40^{\mathrm{ab}}\right)\end{array}$ & $\begin{array}{c}1.89 \\
\left(0.43^{\mathrm{ab}}\right)\end{array}$ & $\begin{array}{c}1.90 \\
\left(0.45^{\mathrm{b}}\right)\end{array}$ & $\begin{array}{c}0.038 \\
(0.012)\end{array}$ \\
\hline Heart & $\begin{array}{c}1.30 \\
(0.29)\end{array}$ & $\begin{array}{c}1.37 \\
(0.30)\end{array}$ & $\begin{array}{c}1.31 \\
(0.30)\end{array}$ & $\begin{array}{c}1.36 \\
(0.32)\end{array}$ & $\begin{array}{c}0.039 \\
(0.009)\end{array}$ \\
\hline Spleen & $\begin{array}{c}0.74^{\mathrm{a}} \\
(0.16)\end{array}$ & $\begin{array}{c}0.72^{\mathrm{ab}} \\
(0.16)\end{array}$ & $\begin{array}{l}0.70^{\mathrm{ab}} \\
(0.16)\end{array}$ & $\begin{array}{c}0.64^{\mathrm{b}} \\
(0.15)\end{array}$ & $\begin{array}{c}0.022 \\
(0.005)\end{array}$ \\
\hline Liver & $\begin{array}{l}10.70 \\
(2.38)\end{array}$ & $\begin{array}{c}9.90 \\
(2.18)\end{array}$ & $\begin{array}{c}9.60 \\
(2.19)\end{array}$ & $\begin{array}{c}9.85 \\
(2.34)\end{array}$ & $\begin{array}{c}0.264 \\
(0.047)\end{array}$ \\
\hline Kidney R & $\begin{array}{c}1.16 \\
\left(0.26^{\mathrm{ab}}\right)\end{array}$ & $\begin{array}{c}1.12 \\
\left(0.25^{\mathrm{b}}\right)\end{array}$ & $\begin{array}{c}1.21 \\
\left(0.28^{\mathrm{a}}\right)\end{array}$ & $\begin{array}{c}1.16 \\
\left(0.28^{\mathrm{a}}\right)\end{array}$ & $\begin{array}{c}0.030 \\
(0.005)\end{array}$ \\
\hline Kidney L & $\begin{array}{c}1.19 \\
(0.26)\end{array}$ & $\begin{array}{c}1.16 \\
(0.25)\end{array}$ & $\begin{array}{c}1.18 \\
(0.27)\end{array}$ & $\begin{array}{c}1.15 \\
(0.27)\end{array}$ & $\begin{array}{c}0.035 \\
(0.007)\end{array}$ \\
\hline Adrenal glands R & $\begin{array}{c}0.022 \\
(0.005)\end{array}$ & $\begin{array}{c}0.023 \\
(0.005)\end{array}$ & $\begin{array}{c}0.020 \\
(0.005)\end{array}$ & $\begin{array}{c}0.022 \\
(0.005)\end{array}$ & $\begin{array}{c}0.003 \\
(0.001)\end{array}$ \\
\hline Adrenal glands L & $\begin{array}{c}0.023 \\
(0.005)\end{array}$ & $\begin{array}{c}0.019 \\
(0.005)\end{array}$ & $\begin{array}{c}0.021 \\
(0.005)\end{array}$ & $\begin{array}{c}0.022 \\
(0.005)\end{array}$ & $\begin{array}{c}0.002 \\
(0.000)\end{array}$ \\
\hline Testis R & $\begin{array}{c}1.87 \\
(0.42)\end{array}$ & $\begin{array}{c}1.88 \\
(0.41)\end{array}$ & $\begin{array}{c}1.98 \\
(0.45)\end{array}$ & $\begin{array}{c}1.93 \\
(0.46)\end{array}$ & $\begin{array}{c}0.061 \\
(0.013)\end{array}$ \\
\hline Testis L & $\begin{array}{c}1.88 \\
\left(0.42^{\mathrm{a}}\right)\end{array}$ & $\begin{array}{c}1.90 \\
\left(0.42^{\mathrm{a}}\right)\end{array}$ & $\begin{array}{c}1.89 \\
\left(0.43^{\mathrm{ab}}\right)\end{array}$ & $\begin{array}{c}1.94 \\
\left(0.46^{\mathrm{b}}\right)\end{array}$ & $\begin{array}{c}0.038 \\
(0.009)\end{array}$ \\
\hline
\end{tabular}

Values in parentheses indicate relative weight of organs $(\mathrm{g} / 100 \mathrm{~g} \mathrm{BW})$

${ }^{a, b}$ Means in the same row bearing different superscripts are significantly different $(p<0.01)$.

meat soup as seasoning increases blood pressure. This increase however is suppressed by adding mugwort to the soup.

\section{Hypertension}

Blood pressure increases even if cardiac output or total peripheral vascular resistance is increased (West, 1990). The factors causing increases in cardiac output are an increase in cardiac function and an increase in extracellular fluid volume. Total peripheral vascular resistance increase is caused by arteriolar vasoconstriction and arteriosclerosis. Essential hypertension in humans can be classified into 4 areas; high renin hypertension, senile hypertension, salt sensitive hypertension, and obesity-related hypertension (Kaplan and Victor, 2010). It has been reported that approximately half of all patients suffering from high blood pressure fall into the salt sensitive hypertension category (Kaplan and Victor, 2010). In the present experiment, systolic blood pressure of animals in GS group and GY group was significantly higher $(\mathrm{p}<0.01)$ than the CP group and GM group (Figure 2). It is thought that this is due to increased salt consumption in these two groups.

\section{Effect of goat meat consumption on blood pressure}

The animals used in the experiment were subjected to a 10 week trial period whereby they were handled daily and their blood pressure was tested in order to familiarize them with the process before the experiment was begun. Heart rate was also measured at the same time as blood pressure measurements were taken.

Table 10. Blood components after the completion of experiment 2 in control (CP), goat meat (GM), goat meat with salt (GS), and goat meat with salt and mugwort (GY) groups

\begin{tabular}{|c|c|c|c|c|c|}
\hline \multirow{2}{*}{ Blood components } & \multicolumn{4}{|c|}{ Groups } & \multirow{2}{*}{ SEM } \\
\hline & $\mathrm{CP}$ & GM & GS & GY & \\
\hline Hematocrit (\%) & 45.42 & 43.92 & 43.90 & 43.67 & 1.043 \\
\hline Leucocyte (/blood $\mathrm{mm}^{3}$ ) & $4,433^{\mathrm{a}}$ & $4,833^{\mathrm{a}}$ & $5,240^{\mathrm{a}}$ & $7,267^{\mathrm{b}}$ & 447.9 \\
\hline Erythrocyte $\left(\times 10^{4} /\right.$ blood $\left.\mathrm{mm}^{3}\right)$ & 847 & 760 & 786 & 873 & 33.3 \\
\hline Hemoglobin (g/dL) & 12.6 & 12.2 & 12.2 & 12.7 & 0.37 \\
\hline
\end{tabular}

Values are indicated by mean \pm SEM of six animals.

${ }^{a, b}$ Means in the same row bearing different superscripts are significantly different $(p<0.01)$. 
Table 11. Plasma components after the completion of experiment 2 in control (CP), goat meat (GM), goat meat with salt (GS), and goat meat with salt and mugwort (GY) groups

\begin{tabular}{|c|c|c|c|c|c|}
\hline \multirow{2}{*}{ Plasma component } & \multicolumn{4}{|c|}{ Groups } & \multirow{2}{*}{ SEM } \\
\hline & $\mathrm{CP}$ & GM & GS & GY & \\
\hline Total protein $(\mathrm{g} / \mathrm{dL})$ & 5.90 & 5.67 & 5.80 & 5.70 & 0.139 \\
\hline Albumin (g/dL) & $3.42^{\mathrm{a}}$ & $2.32^{\mathrm{b}}$ & $3.20^{\mathrm{a}}$ & $3.35^{\mathrm{a}}$ & 0.112 \\
\hline Total bilirubin (mg/dL) & $0.62^{\mathrm{a}}$ & $0.23^{\mathrm{b}}$ & $0.26^{\mathrm{b}}$ & $0.38^{\mathrm{b}}$ & 0.042 \\
\hline Glucose (mg/dL) & 121.17 & 97.50 & 118.25 & 124.67 & 6.034 \\
\hline GOT (IU/L) & $74.75^{\mathrm{a}}$ & $23.33^{\mathrm{b}}$ & $24.50^{\mathrm{b}}$ & $35.17^{\mathrm{b}}$ & 2.897 \\
\hline GPT (IU/L) & $25.25^{\mathrm{a}}$ & $10.00^{\mathrm{b}}$ & $10.00^{\mathrm{b}}$ & $12.00^{\mathrm{b}}$ & 1.140 \\
\hline Total cholesterol (mg/dL) & 55.92 & 43.91 & 45.22 & 58.31 & 4.108 \\
\hline HDL-cholesterol (mg/dL) & $25.97^{\mathrm{ab}}$ & $19.83^{\mathrm{a}}$ & $23.58^{\mathrm{ab}}$ & $29.98^{\mathrm{b}}$ & 1.816 \\
\hline LDL-cholesterol (mg/dL) & 8.81 & 6.39 & 4.57 & 11.28 & 3.691 \\
\hline Free fatty acid $(\mu \mathrm{Eq} / \mathrm{L})$ & $1,351.09$ & $1,397.82$ & $1,124.41$ & 827.62 & 216.232 \\
\hline Phosphatide (mg/dL) & $75.50^{\mathrm{a}}$ & $58.29^{\mathrm{a}}$ & $73.74^{\mathrm{a}}$ & $95.76^{\mathrm{b}}$ & 4.206 \\
\hline Triglyceride (mg/dL) & 105.72 & 88.45 & 85.36 & 85.27 & 9.354 \\
\hline
\end{tabular}

Values are indicated by mean \pm SEM of six animals.

${ }^{a, b}$ Means in the same row bearing different superscripts are significantly different $(\mathrm{p}<0.01)$.

The heart rates of all the animals in the groups in experiment 1 (375.9 \pm 4.8 beats $/ \mathrm{min})$ were lower than the average for Dahl/Iwai rats ( $464.2 \pm 19.8$ beats $/ \mathrm{min})$ based on measurements provided by Nippon SLC (Hamamatsu, Japan) (Ideishi et al., 1994). The lower heart rates indicate lower sympathetic function activity levels due to the animals' familiarity with experimental manipulation. In experiment 1 , the animals in the CP group consumed $45.9 \pm 0.4 \mathrm{~g}$ fresh chicken meat $/ \mathrm{d} / \mathrm{kg}$ BW $(11.3 \pm 0.1 \mathrm{~g}$ $\mathrm{DM} / \mathrm{d} / \mathrm{kg} \mathrm{BW}$ ) for a 14 week period. In contrast, the animals in the GM, GS, and GY groups consumed $34.8 \mathrm{~g}$ fresh goat meat $/ \mathrm{kg} \mathrm{BW}$ (11.3 g dry matter $/ \mathrm{kg} \mathrm{BW}$ ) (Tables 2, 3 , and 4). The animals in the GM group had a systolic blood pressure of $126.2 \pm 1.6 \mathrm{~mm} \mathrm{Hg}$ and a diastolic blood pressure of $98.8 \pm 2.4 \mathrm{~mm} \mathrm{Hg}$. This was similar to the CP group animals' systolic $(125.4 \pm 2.0 \mathrm{~mm} \mathrm{Hg})$ and diastolic $(97.6 \pm 2.3 \mathrm{~mm} \mathrm{Hg}$ ) blood pressure (Figure 2). This shows that extended periods of chicken or goat meat consumption do not increase blood pressure. The animals in the GM group of this experiment had markedly lower systolic blood pressure than Dahl/Iwai rats that consumed feed containing $0.2 \% \mathrm{NaCl}$ (F2 food: Funabashi Farm, Funabashi, Japan) (approximately $140 \mathrm{~mm} \mathrm{Hg}$ ) (Iwasa et al., 2000). The contributing factor to these lower measurements is thought to be the rats' familiarization of the blood pressure measurement process in this experiment. Goat meat contains high levels of taurine (Nagamine et al., 2013). It was reported that taurine is an effective antihypertensive agent for salt-induced hypertension (Ideishi et al., 1994; Nagamine et al., 2013).

Factors related to increased blood pressure in conjunction with the consumption of goat meat dishes

Salt is used as seasoning in goat meat dishes on the main island of Okinawa (Hirakawa, 2008). In experiment 1, animals in the CP and GM groups consumed feed

Table 12. Renal function pertinent details and plasma electrolyte concentration after the completion of experiment 2 in control (CP), goat meat GM), goat meat with salt (GS), and goat meat with salt and mugwort (GY) groups

\begin{tabular}{|c|c|c|c|c|c|}
\hline \multirow{2}{*}{ Plasma component } & \multicolumn{4}{|c|}{ Groups } & \multirow{2}{*}{ SEM } \\
\hline & $\mathrm{CP}$ & GM & GS & GY & \\
\hline Creatinine (mg/dL) & $0.85^{\mathrm{a}}$ & $0.52^{\mathrm{b}}$ & $0.60^{\mathrm{bc}}$ & $0.75^{\text {ac }}$ & 0.051 \\
\hline Urea nitrogen (mg/dL) & 16.33 & 15.50 & 17.00 & 14.83 & 0.825 \\
\hline Plasma osmolality (mOsm/L) & $314.40^{\mathrm{a}}$ & $302.67^{\mathrm{ab}}$ & $307.00^{\mathrm{ab}}$ & $300.00^{\mathrm{b}}$ & 2.854 \\
\hline $\mathrm{Na}(\mathrm{mmol} / \mathrm{L})$ & 132.33 & 127.33 & 130.00 & 131.67 & 1.475 \\
\hline $\mathrm{K}(\mathrm{mmol} / \mathrm{L})$ & $7.30^{\mathrm{a}}$ & $6.15^{\mathrm{ab}}$ & $5.34^{\mathrm{ab}}$ & $4.82^{\mathrm{b}}$ & 0.458 \\
\hline $\mathrm{Cl}(\mathrm{mmol} / \mathrm{L})$ & 99.83 & 93.00 & 93.20 & 96.00 & 1.781 \\
\hline $\mathrm{Ca}(\mathrm{mg} / \mathrm{dL})$ & $11.18^{\mathrm{a}}$ & $9.87^{\mathrm{b}}$ & $10.82^{\mathrm{ab}}$ & $11.23^{\mathrm{a}}$ & 0.279 \\
\hline Inorganic phosphorus (mg/dL) & $5.85^{\mathrm{a}}$ & $3.98^{\mathrm{b}}$ & $5.34^{\mathrm{ab}}$ & $5.30^{\mathrm{ab}}$ & 0.401 \\
\hline $\mathrm{Mg}(\mathrm{mg} / \mathrm{dL})$ & $2.65^{\mathrm{a}}$ & $1.68^{\mathrm{b}}$ & $1.90^{\mathrm{b}}$ & $2.05^{\mathrm{b}}$ & 0.118 \\
\hline
\end{tabular}

Values are indicated by mean \pm SEM of six animals.

${ }^{\mathrm{a}, \mathrm{b}}$ Means in the same row bearing different superscripts are significantly different $(\mathrm{p}<0.01)$. 
containing $0.3 \%$ salt content $(0.169 \mathrm{~g} \mathrm{NaCl} / \mathrm{d} / \mathrm{kg} \mathrm{BW})$ for a 14 week period (15 weeks of age to 29 weeks of age). Experiment 2 saw them consume the same feed for a further 4 weeks ( 30 weeks of age to 33 weeks of age). The animals in the GS and GY groups were given feed containing $3 \%$ salt content (1.689 g NaCl/d/kg BW) between 15 and 19 weeks of age. Between 20 and 29 weeks of age, the salt content in the feed of the GS and GY groups was increased from $3 \%$ to $4 \%$ (2.252 $\mathrm{g} \mathrm{NaCl} / \mathrm{d} / \mathrm{kg} \mathrm{BW})$. The feed given to the GY group contained 5\% freeze dried mugwort powder (Tables 2, 3, and 4). The blood pressure of the animals, up until 19 weeks of age, in the GS and GY groups (systolic blood pressure 124.0 $\pm 2.3,125.6 \pm 2.2 \mathrm{~mm} \mathrm{Hg}$, diastolic blood pressure $92.1 \pm 2.1,88.4 \pm 3.1 \mathrm{~mm} \mathrm{Hg}$ ) was virtually equal to the CP group (systolic blood pressure 122.8 \pm 3.7 , $93.0 \pm 2.6$ ). From 20 weeks of age however, blood pressure either increased significantly $(\mathrm{p}<0.01)(\mathrm{GS}$ group) or showed a tendency to increase (GY group) (systolic blood pressure $143.3 \pm 4.4,135.5 \pm 3.1 \mathrm{~mm} \mathrm{Hg}$, diastolic blood pressure $110.9 \pm 3.7,104.7 \pm 2.6 \mathrm{~mm} \mathrm{Hg}$ ) (Figure 2). The reason for the increase in blood pressure is a marked increase in circulating plasma volume caused by an increase in plasma osmolality due to the retention of excessive salt in the blood as the animals' urinary sodium excretion capacity was exceeded between 20 and 29 weeks of age.

In experiment 2, when the salt content in feed given to 30 week old rats in the GS and GY groups was reduced from $4 \%$ to $0.3 \%$, blood pressure (systolic blood pressure $132.0 \pm 3.8,129.4 \pm 2.8 \mathrm{~mm} \mathrm{Hg}$, diastolic blood pressure $106.1 \pm 2.4,103.7 \pm 2.7 \mathrm{~mm} \mathrm{Hg}$ ) recorded after 30 weeks of age returned to levels observed in the $\mathrm{CP}$ group (systolic blood pressure $127.5 \pm 0.5 \mathrm{~mm} \mathrm{Hg}$, diastolic blood pressure $101.7 \pm 0.8 \mathrm{~mm} \mathrm{Hg}$ ) (Figure 4). This result is proof that the increase in blood pressure in the animals of the GS and GY groups was caused by the increase in salt consumption. The $4 \%$ salt content used in this experiment was purposely higher than the salt levels (approx. 2.5\%) used for seasoning goat soup (Hirakawa, 2008). Watanabe et al. (2007) reported that systolic blood pressure in rats increased when raised on feed containing $2.3 \% \mathrm{NaCl}$ compared to rats given feed with $0.3 \% \mathrm{NaCl}$ or Japanese soybean paste. These results indicate that while prolonged consumption of goat meat does not increase blood pressure, the consumption of goat meat dishes seasoned with high amounts of salt (3\% to $4 \%$ ) does increase the blood pressure in hypertensive patients. The systolic blood pressure of animals in the GY group tended to be lower than the GS group. Sugimoto et al. (1998) reported that rutin (flavonoid compound) in mugwort could be a major active component for reducing blood pressure in spontaneously hypertensive rats (SHR). This indicates that the addition of mugwort to goat meat soup suppresses blood pressure increases (Figure 2).

\section{Dieting effects of mugwort}

The feed used in this experiment was formulated based on AIN-93 Purified Diets for Laboratory Rodents (American Institute of Nutrition, 1993). The feed was then palletized for ease of consumption. The feed given to the different groups in this experiment was highly palatable. The animals were given amounts of feed able to be completely consumed in a day. Upon conclusion of experiment 1 , the body weight of the 29 week old animals in the GM group $(434.3 \pm 4.6 \mathrm{~g} / \mathrm{head})$, the GS group $(420.5 \pm 5.0 \mathrm{~g} / \mathrm{head})$ was approximately the same as the CP group $(427.0 \pm 7.1 \mathrm{~g} / \mathrm{head})$. The animals in the GY group $(395.6 \pm 5.2 \mathrm{~g} / \mathrm{head})$ however, were significantly $(\mathrm{p}<0.01)$ lighter. It is thought that dieting effect observed was due to the combination of higher crude dietary fiber and lower energy levels in the GY group feed (Sugimoto et al., 1998; Takatera et al., 2009). The water intake of the GS and GY groups over the 14 weeks of the experiment was significantly higher $(\mathrm{p}<0.01)$ than the $\mathrm{CP}$ and $\mathrm{GM}$ groups. However, in experiment 2, the reduction in salt content in the GS and GY groups' feed caused a decrease in water intake to levels observed in the CP and GM groups (Figure 3 ). It is thought that the drinking behavior observed in the GS and GY groups was caused by the thirst sensations brought about by increased plasma osmolality due to the increase in the salt content in the feed.

\section{Effect of goat meat consumption on blood parameters}

Upon completion of the experiment at 33 weeks of age, the animals used in the experiments were slaughtered, their blood parameters and organ wet weight was measured, and the carcasses were macroscopically inspected. Plasma creatinine concentration and plasma urea nitrogen concentration, both indicators of renal dysfunction, GOT and GPT activity, indicators of hepatic dysfunction, and total cholesterol, free fatty acid, phospholipid, and triglyceride concentrations which are indicators of nutritional state, were all similar in the GM, GS, and GY groups when compared to the CP group (Tables 11 and 12).

The wet weight of the organs in all three treatment groups was all similar to the $\mathrm{CP}$ group. There were no visible signs of abnormality in the organs. This indicates that in animals with reduced renal function, while an increase in feed salt content to $4 \%$ caused an increase in blood pressure, this did not result in any irreversible dysfunction to the liver and kidneys. The experiment was begun when the rats were 15 weeks of age. The appetites of the rats were bigger and they were more active than Wister rats being raised at the same time. It is thought that this is why there were no signs of increased peripheral vascular vessel resistance caused by age related senile hypertension. 
The heart rate of the animals was low and stable throughout the experiment (Table 5). It is therefore thought that increased cardiac output caused by sympathetic hyperactivity related heart rate and cardiac contractile force increases did not cause hypertension. It is thought that the increased blood pressure in the rats in the experiment was due to an increase in circulating plasma volume caused by excessive salt intake that led to renal salt excretion capacity being exceeded.

The results indicate that as in the case of chicken consumption, while extended periods of goat meat consumption does not cause an increase in blood pressure, prolonged consumption of goat meat dishes prepared with high salt content for seasoning does cause an increase in blood pressure in animals and humans with decreased renal function.

\section{ACNOWLEDGEMENTS}

We are grateful for the assistance of University of the Ryuykus Emeritus Professor Fujiya Hongo, Mr. Shoei Taira (NFC Co., Ltd), and Mr. Tetsuya Toyokawa of the Okinawa Institute of Technology. We thank Mr. Daiki Nagai, Mr. Kenji Suzuki, Mr. Keisuke Ninomiya and Mr. Yoshifumi Fukuda for their helpful assistance in experiments. We also thank Mr. Glenn McIlvride for his English proof-reading on this manuscript. The computation was mainly carried out using the computer facilities in the Research Institute for Information Technology, Kyushu University.

\section{REFERENCES}

AOAC. 1990. Official methods of analysis. 15th. Ed. Association of Official Analytical Chemists, Arlington, Virginia.

Chen, Y. L., H.C. Hauang, Y. I. Weng, Y. J. Yu, and Y. T. Lee. 1994. Morphological evidence for the antiatherogenic effect of scoparone in hyperlipidaemic diabetic rabbits. Cardiovasc. Res. 28:1679-1685.
Ideishi, M., S. Miura, T. Sakai, M. Sasaguri, Y. Misumi, and K. Arakawa. 1994. Taurine amplifies renal kallikrein and prevents salt-induced hypertension in Dahl rats. J. Hypertens. 12:653661

Iwasa, Y., K. Shimoyama, K. Aoki, K. Ohya, and H. Uematsu. 2000. The effect of high salt intake on the mandibular bone loss in Dahl-Iwai salt-sensitive rat. J. Med. Sci. 47:187-195.

Hirakawa, M. 2008. Studies on the improvement of meat and milk productivity of goats in the subtropical Okinawa. Ph.D. thesis. Kagoshima Univ.

Kaplan, N. M. and R. G. Victor. 2010. Primary hypertension: pathogenesis. KAPLAN'S Clinical Hypertension. pp. 42-107.

Nagamine, I., K. Sunagawa, and T. Kina. 2013. Use of Awamoripressed lees and Tofu lees as feed ingredients for growing male goats. Asian Australas. J. Anim. Sci. 26:1262-1275.

Reeves, P. G., F. H. Nielsen, and G. C. Fahey. 1993. AIN-93 Purified diets for laboratory rodents: Final Report of the American Institute of Nutrition Ad Hoc Writing Committee on the Reformulation of the AIN-76A Rodent Diet. J. Nutr. 123:1939-1951.

SAS. 1990. SAS/STAT user's guide: volume 2, version 6.4th Ed. SAS Institute Inc., SAS Campus Drive, Cary, NC 27523.

Sugimoto, M., T. Kawanabe, and K. Hasegawa. 1998. Effects of Okinawa Yomogi (Artemisia Princeps Pampan) on blood pressure and lipid metabolism in spontaneously hypertensive rat (SHR). J. Kagawa Nutr. Univ. 29:37-45.

Takatera, K., H. Ogawa, K. Yamamoto, N. Kanou and Y. Kunimoto. 2009. Effects of Yomogi extract on lipid metabolism in stroke-prone spontaneously hypertensive rats. Nippon Shokuhin Kagaku Kogaku Kaishi. 56:48-52.

Watanabe, H., M. Yoshida, K. Mizuno, and K. Kamiya. 2007. Miso (Japanese soybean paste) diet conferred greater protection against hypertension in Dahl salt-sensitive rats. Miso Science and Technology 55:299-310.

Weinberger, M. H., J. Z. Miller, F. C. Luft, C. E. Grim, and N. S. Fineberg. 1986. Definitions and characteristics of sodium sensitivity and blood pressure resistance. Hypertension 8:127134.

West, J. B. 1990. Heart failure, hypertrophy, and other abnormal cardiovasculatory states. Best and Taylor's Physiological Basis of Mdedical Practice (12th Ed.). Williams and Wilkins. Baltimore. pp. 307-330. 